\title{
Para entender la postmodernidad
}

La postmodernidad es la expresión de una conciencia fragmentaria, del sincretismo de las visiones. De los sistemas unitarios se ha pasado a una sensibilidad del particularismo, la diseminación y el disenso.

Postmodernidad significa inhibición respecto a los asuntos públicos. Ya no se invierte afectivamente en los grandes sistemas ideológicos. El joven se retrotrae al grupó de iguales y se adormece en el alcohol de una cultura de litronas. Todos los estereotipos sobre nuestra cultura apuntan a una evasión de la realidad. No solamente ya no se espera poder interpretar el mundo, sino que tampoco se espera poder transformarlo: Prometeo se dejó devorar las entrañas por una empresa sin sentido. Por ello todo cambio histórico radical hacia la justicia aparece como un círculo cuadrado histórico. En definitiva, se tiene la experiencia de un mundo duro, sórdido, envuelto en 'divinas palabras' que no se acepta pero que no se espera poder cambiar. Muere el mito del cambio social y el desengaño hace mella en los valores. La ética del 'todo vale se instala en todos los corazones. La postmodernidad es un estado de ánimo, el resultado de un desengaño: el mundo es un valle de lágrimas, pero no hay otra patria. Sólo queda el 'pequeño placer'.

\section{LA JUVENTUD POSTMODERNA}

El consumismo, con su lujuria de los objetos, produce tipos cada vez más narcisistas. El narciso vive obsesionado con la propia imagen, preocupado de sí mismo ${ }^{1}$. Para él vivir equivale a sentir sensaciones, cuanto más fuertes mejor. Obligada a una adolescencia forzosa prolongada por el paro y la duración de los estudios, la juventud experimenta una moratoria en la asunción de

1. Amando de Miguel, Los narcisos. Kairós, Barcelona 1979. 
responsabilidades ${ }^{2}$. Es la juventud guapa de nuestros días. Jóvenes ucrónicos, sin futuro (lo sienten amenazado), sin memoria.

El tipo puro de narciso es el pasota, ser ombligocéntrico y descomprometido, pues el pasota pasará de todo menos, evidentemente, de sí mismo. Como no hay futuro, la salvación acontece en el presente, es instantánea y se produce en la aceleración de las experiencias (adicción a los $\mathrm{km} / \mathrm{h}$, el stereo, la droga). Si nos esperamos nos volvemos viejos. Es el lema ${ }^{3}$.

\section{LA POSTMODERNIDAD FILOSÓFICA}

La postmodernidad no es sólo un estilo de vivir. Es también un modo de pensar. La modernidad prometió que una razón libre engendraría una sociedad libre. Los postmodernos ven las diferencias entre las promesas y la realidad. La crítica romántica a la racionalidad ilustrada es un antecedente: la sinrazón de los fines, la búsqueda de lo excepcional, el predomino de lo instintivo y efímero, la exaltación del sujeto y la estética, etc. La crítica a la modernidad se concreta en los puntos siguientes ${ }^{4}$ :

a) Desencanto de la razón: La razón no es un espejo de la realidad. Ya Marx advirtió que el conocimiento ofrece la imagen interesada y parcial de los detentadores del poder. Para Nietzsche, tras los conceptos, anida el ansia de poder y el resentimiento. «Desconfía de quien te dice: ten cuidado, sólo busca que no escapes a su lado», canta J. Sabina. Freud nos remite al inconsciente donde las razones son la disculpa de nuestros deseos, miedos y rechazos. Heidegger advierte en el pensamiento occidental una tendencia a la objetivización, el cálculo y el raciocinio que olvida otras dimensiones de lo real. Wittgenstein nos enseña a la razón atrapada en la red del lenguaje vinculado a la historia y al estilo de vida del colectivo humano. La razón humana piensa a través de este lenguaje. Se genera un socratismo pesimista que sabe demasiado sobre las miserias de la razón.

b) La aceptación de la pérdida de fundamento: la razón no puede establecer, sin incurrir en sospecha de encubrimiento, ningún punto fijo donde anclar el barco de la reflexión. Esto producía turbación en los modernos (Descartes y su búsqueda de lo claro y distinto). El postmoderno no llora la pérdida de seguridad. Se avista un tiempo de indeterminación.

2. Moncada, A., La adolescencia forzosa. Dopesa, Barcelona 1979.

3. DíAZ, C., ¿Es grande ser joven?, Encuentro, Madrid 1980.

4. Mardones, J.M., Postmodernidad y cristianismo. Sal Terrae, Santander 1988. 
c) El rechazo de los grandes relatos ${ }^{5}$ : si no hay posibilidad de fundar nuestras visiones de la realidad sobre tierra firme, ¿qué son las grandes visiones filosóficas, políticas y religiosas típicas de la modernidad? Según Lyotard, son grandes relatos, narraciones que buscan dar coherencia y sentido a nuestra experiencia de la vida y a la colectividad humana. No pueden tener pretensiones de objetividad, son puras narraciones. Además es necesario desvelar su peligrosidad; tras ellas se esconde un uniformismo totalitario. Los grandes relatos o metarrelatos fascinan por su oferta de sentido y salvación. Pero estos grandes relatos emancipatorios han justificado la barbarie, desde el marxismo al cristianismo. Tras ellos anida la legitimación del terror, la eliminación de las diferencias y la imposición militar, mecánica o espiritual del uniformismo. La postmodernidad consiste muy esencialmente en la increencia en los metarrelatos, en la oposición a los uniformismos disciplinadores. Hay que vivir en la heterogeneidad. La ética sólo puede ser provisional y tentatoria ${ }^{6}$.

d) El fin de la historia: al renunciar a los grandes relatos despedimos el sentido de la historia (adiós a los mitos de progreso, emancipación y salvación). Pero ello no representa una tragedia, sino precisamente la ocasión para realizarse. Vivimos en una inmediatez errática, la era de la simulación y el éxtasis de la comunicación.

e) La estetización general de la vida como política: la razón pasa a ser un instrumento fruitivo, no-objetivante. Se pierde un concepto fuerte de razón. Para los postmodernos esto supone una visión de la riqueza de la vida. Pero el abandono de lo universal es peligroso, nos deja indefensos ante el poder ( $\mathrm{Ha}$ bermas) y hace derivar la postmodernidad hacia el neoconservadurismo.

Conviene no olvidar la importancia que el marxismo ha tenido en este proceso. A través de él, la modernidad confundió la solidaridad con el mito milenarista del cielo en la tierra. La postmodernidad no niega los análisis marxistas, sino sus soluciones, sus promesas no cumplidas. Marx quiso eludir la travesía por el desierto disfrazando sus ideales de ciencia e hizo perder fundamento a la ética. Pero una vez que esta maniobra quedó en evidencia ¿por qué habríamos de ser generosos? se preguntan los postmodernos inaugurando así una nueva etapa de nuestra cultura al grito de: Marx ha muerto jviva Rambo!

5. LyotaRd, J.F., La condición postmoderna. Cátedra, Madrid 1984.

6. CAmps, V., La imaginación ética. Seix Barral, Barcelona 1983. 
RAÍCES SOCIALES DE LA POSTMODERNIDAD:

a) Lo económico como central: ": la pérdida de centralidad de la religión se hizo en favor de lo económico. Entonces la razón se escoró hacia lo instrumental y lo funcional.

b) Un mundo burocratizado ${ }^{8}$ : el ingente desarrollo industrial y económico requería organización, también el aparato administrativo del Estado. La burocracia respoñde a una lógica de dominación y jerarquización. Se trata de una eliminación tangencial de la democracia en manos de los especialistas, de una difusión de lo standàr y uniforme. Frente a ella, la postmodernidad representa una reacción a la penetración del sistema. La apatía es una forma de resistencia por retraimiento. Pero esta dejación de responsabilidad deteriora gravemente el ambiente humano.

c) Un mundo de cosmovisiones fragmentadas: frente a la razón instrumental se descubrió que en la razón anidan diversas dimensiones: científica, ético-política, estética, etc. Se diferencian causando un pluralismo de racionalidades y saberes. Ya no hay «razón». La postmodernidad es reticencia frente a la razón como poseedora de un saber fuerte. No son ateos humanistas sino nihilistas positivos que no miran trágicamente la existencia sin absoluto. La realidad desfundada es ocasión para elegir y dar valor a lạs cosas.

\section{POSTMODERNIDAD Y CRISTIANISMO ${ }^{9}$}

La postmodernidad cambia el discurso del mundo sobre la Iglesia. Antaño se la atacaba por infiel a la utopía. Ahora se dice que la Iglesia no tiene utopía. De esta manera la postmodernidad se justifica a sí misma en su misma falta de aliento utópico. Por eso ya sólo se cree en el tipo de vida que genera las palabras en una praxis que haga realidad la verdad y «la verdad, Pilatos, es ponerse del lado del pobre» (Mounier). Ha terminado la historia, pero era la historia de los vencedores, la historia de las grandes palabras escrita por sus disfrutadores. Ahora tras esa historia aparece la verdad, el sufrimiento, el hambre, la víctima. Todo ello porque la tarea fundamental de occidente ha sido transformar el valor de uso en valor de cambio y esta operación caracteriza

7. Weber, M., Economía y sociedad. F.C.E., México 1964.

8. Salustiano del Campo (Ed.), Tratado de sociología. v. II, Cfr. artículo de Julio Rodríguez Aramberri, Organización.

9. GonZÁlez FAUS, J.I., La interpelación de las iglesias latinoamericanas... F. Santa María, Madrid 1988. 
toda desvalorización. En la acepción nietzschiano-heideggeriana el nihilismo consiste en transformar el valor de uso en valor de cambio. Es la reducción de los demás a la condición de mercancía. Para la postmodernidad la generosidad es inútil, nadie tiene que morir por nadie, aunque para que nosotros no muramos ni un poco, muchos mueren del todo. La Iglesia ya no debe ser compañera de viaje, como lo debió ser críticamente en la modernidad, sino alternativa. Para ello ha de recuperar la utopía vivida, es decir, el evangelio. Si éste es declarado inviable para la vida pública eclesial, la postmodernidad habrá ganado la batalla.

Además, nos advierte sobre la necesidad de una purificación de todo concepto de Dios. La Iglesia no puede tener una teoría fuerte de Dios. La teología es un pensamiento débil que merodea el absoluto. Pero, peligrosamente, la postmodernidad tiende a hacer del cristianismo una religión light, un esteticismo gustativo.

Lo cierto es que la crítica postmoderna ha llegado inoportunamente para la Iglesia que apenas había llegado a comprender a la modernidad y ahora debe cambiar de interlocutor. Frente a esta cultura de la desgana, la Iglesia ha de ser voz de los pobres, de hablar desde el reverso de la historia, llamada persistente a la solidaridad.

\section{INCREENCIA Y MODERNIDAD:}

Resulta importante señalar algunas instituciones sociales que tienen su origen en la modernidad y que son fuertemente configuradoras de la conciencia de los individuos, con vistas a determinar qué tipo de pensamiento inducen (la práctica social determina el conocimiento).

1. El sistema de producción industrial: ha producido una colonización de la vida por las dimensiones instrumentales. Creador del homo faber. Se lleva a cabo un trasvase de mentalidad desde el campo del dominio de la naturaleza al de las relaciones interpersonales. Weber expresó esta idea comparando la razón teleológica (se busca un fin valorando los medios más apropiados y teniendo en cuenta las consecuencias, los fines se convierten a su vez en medios para otros fines) con la razón axiológica (el fin viene impuesto por las creencias, no cualquier medio vale y las consecuencias no son tenidas en cuenta). Este último modelo de racionalidad corresponde a la religión ${ }^{10}$. La fascinación por la ciencia lleva a una visión plana de la realidad. El mundo de las creencias se privatiza dominado por el politeísmo. La naturaleza ya no es lo

10. WEBER, M., o.c. 
transido de divinidad, el hogar misterioso que nos rodea y alimenta. Sobre ella se ejercerá un dominio y una explotación, cuya racionalidad terminará por trasvasarse al dominio de lo interpersonal, tal como los ecologistas habían advertido: "como se trata a la naturalezà se termina tratando a los hombres»"

2. El mercado ideológico: una pluralidad de cosmovisiones compiten por la salvación del hombre. La democracia es una renuncia a la unanimidad social y un reconocimiento de que ha de convivirse con la duda. Al caer el monopolio cosmovisional cristiano, el relativismo y el escepticișmo se irán imponiendo, así como la inseguridad psicológica. Los cristianos se convierten en minoría cognitiva, la plausibilidad social de la fe disminuye y con ella su relevancia ${ }^{12}$. Como hizo notar Berger, ello nos sitúa ante una encrucijada: a mayor identidad del grupo menor relevancia; para hacerse más relevantes hay que negociar más la propia identidad. En todo caso asistimos a un claro proceso de invisibilización de la religión cada vez más recluida en lo privado ${ }^{13}$.

3. El regreso de lo religioso: se trata de la vuelta de lo reprimido, pero acontece de una forma trivializada: sectas, horóscopos, ovnis. Es un politeísmo postcristiano ${ }^{14}$. El neoconservadurismo intenta recomponer el capitalismo recuperando una ética puritana. Ésta forma de recuperar la transcendencia no se preocupa de analizar la injusticia del sistema. También los nuevos movimientos sociales (pacifismo, ecologismo) al reformar posturas éticas sacándolas de su reclusión en lo privado, crean una situación propicia para el advenimiento de lo religioso.

La modernidad nos obliga a vivir la fe a la intemperie sin abrigos sociales (ante Dios como si Dios no existiera). Pero nuevamente y sobre todo, recordar que cualquier defensa que no sea la de los débiles provoca la llegada de la amoralidad.

\section{LA SOCIEDAD DE CONSUMO}

El consumo es otra institución social heredada de la modernidad, su importancia es tal que merece un amplio tratamiento, pues está detrás de muchos de los fenómenos sociales mencionados.

La economía clásica estudió la producción, pero no el consumo, dando por sentado el comportamiento racional del consumidor que distribuye sus in-

11. Roszak, Th., Persona/planeta. Kairós, Barcelona 1985.

12. Berger, P., Rumor de ángeles. Herder, Barcelona 1975.

13. LuCKMANN, La religión invisible. Sígueme, Salamanca 1973.

14. Mardones, J.M., Modernidad y cristianismo. 
gresos según las necesidades para maximizar el bienestar. Los gustos y necesi-. dades no tenían por qué ser explicados por la ciencia económica a pesar de su incidencia en el proceso productivo. La economía formal destaca la soberanía del individuo, que a través de sus actos de compra determina qué se produce y cuánto ${ }^{15}$.

Pronto empezaron las críticas a causa del carácter manipulador de la publicidad, críticas que pecaron de psicologicistas. Veblen llevó a cabo el primer intento moderno de estudiar el comportamiento del consumidor. El consumo de la clase más alta marca la pauta al resto. Las pautas de consumo son normas sociales para el status correspondiente. Por tanto, la posesión y utilización de objetos es vivida como signo de clase. Estos análisis terminaban con la idea de la soberanía del consumidor. Pero el gran estudioso postmoderno del consumo es J. Baudrillard y a él voy a seguir en la exposición. La antropología inducida en el individuo, que lee su vida a la luz de un código económico, constituye el punto de partida en el estudio del «ser» de nuestros contemporáneos ${ }^{16}$.

1. El consumo como ambiente: el consumo es una evidencia que nos rodea, no estamos rodeados propiamente de otros hombres, sino por objetos. Los grandes almacenes son el exponente del consumo como ambiente. En ellos se da la desaparición del dinero líquido signo de la fecalidad de la vida real, para, de este modo, conducirnos hasta un mundo irreal, cálido, donde el bien producido se presenta como «don» entregado. Estos objetos ordenados en series nos llevarán siempre a comprar lo que esté en el límite de nuestras posibilidades económicas. Del mismo modo que el niño-lobo se convertía en lobo al convivir entre lobos desde los primeros momentos de su vida, así nosotros «devenimos» funcionales entre los objetos con los que convivimos.

2. El consumo como mito ${ }^{17}$ : consumir es participar de un pensamiento mágico: la creencia en el poder de los signos. Las pequeñas satisfacciones consumidas constituyen prácticas de exorcismo a través de las cuales se cree poder captar el bienestar total, la felicidad. Los beneficios de la producción no son vividos como producidos sino como milagro. Los bienes de consumo se proponen como poder captado, no como productos trabajados. La mercancía es dispensada por una instancia mitológica benéfica: la técnica, el progreso. $\mathrm{Pe}$ ro a través del consumo, de la TV, no captamos la realidad sino los signos

15. Salustiano del Campo, (Ed.), Tratado de sociología, v. II. Cfr. artículo de Manuel Navarro López, Economía.

16. Baudrillard, J., El espejo de la producción. Gedisa, Barcelona 1978.

17. Baudrillard, J., La societé de consomation, Denoel, Paris 1970. 
conjurados de la realidad. La opulencia no es más que acumulación de los «signos» de la felicidad en la esperanza de apropiarse así de la Felicidad. Esta Felicidad está detrás del viaje a Canarias o las sales de baño como instancia mítica a la que apelar. Para ello es necesario que la Felicidad se convierta en cuantificable, mensurable a través de los objetos y signos de confort en cuya eficacia, aquí está lo mágico, se cree.

3. El consumo como simulación: los media no nos envían al mundo, nos dan a consumir signos. Se puede definir la praxis del consumo, la relación del consumidor con lo real, no cómo interés o responsabilidad comprometida, sino como curiosidad y desconocimiento. Lo real, es consumido a distancia (condición del signo). Esa realidad desubstancializada por la pantalla de TV, abre la cotidianidad clausurada al simulacro del mundo. La cotidianidad representa la esfera de lo inmanente. Pero sería insoportable si los individuos no pudieran alimentarse de los signos de lo transcendente (político, social, cultural). Tenemos necesidad de abrir nuestra privaticidad, si no a lo real, al menos al simulacro de lo real. Esta función es cumplida ejemplarmente por la TV, especie de ventana invertida que da a nuestra habitación. En ella, las imágenes de la exterioridad (frecuentemente sórdida) se vuelven íntimas, cálidas, con un calor perverso. Se conjuran de este modo convertidas en espectáculo. La desarticulación de lo real en signos sucesivos y equivalentes se realiza en la pantalla a través de la transición de imágenes, desde la guerra o el hambre del tercer mundo a los anuncios de coca-cola o la música-hall. El espectáculo está contra el sentido. Más que nunca el medio es el mensaje (McLuhan). Los medios de comunicación de masas tienen por función neutralizar el carácter vivido, único, del mundo por un mundo homogéneo en que los contenidos se asimilan entre sí. Las imágenes de TV se convierten en metalenguaje de un mundo ausente. Esto parece diáfano cuando observamos que los sucesos significados por la imagen se agotan en la duración de su absorción, en su consumo. Publicidad y noticia constituyen una misma sustancia visual, fónica y mítica, suscitan la misma absorción y curiosidad.

El consumo realiza la exclusión del mundo. Mediante las estrategias del deseo se desculpabiliza la pasividad que está en contradicción con la moral moderna del compromiso militante. Para resolver el conflicto que esta moral plantea frente al hedonismo consumista, se presenta la quietud de la esfera privada como un valor amenazado. Es necesaria la violencia e inhumanidad del mundo exterior para que la cotidianidad busque reforzarse en su seguridad. La fatalidad es sugerida para alimentar la banalidad. Ya sólo una pareja mítica despierta interés: el parte metereológico (obsesión por lo solar) y los accidentes de carretera (letanía de la muerte). Los demás hechos han desaparecido en su especificidad, atrapados por la discursividad del medio de comunica- 
ción cuyo mensaje de total insustancialidad descodifica inconscientemente el telespectador.

4. El consumo como lógica de la diferenciación: el consumo es un proceso de clasificación y diferenciación social. Los objetos se consumen no por razón de su utilidad funcional, sino en virtud de su condición de signos de prestigio y status social. Consumir objetos es consumir diferencias sociales. Esa diferencia consumida es seductora. Pero precisamente queriendo diferenciarnos, personalizarnos, nos alienamos, pues nos integramos en la serie. En efecto, las diferencias son producidas industrialmente. El sistema elimina el conte-nido propiamente diferenciador de cada uno, su «ser» para poner esa forma diferencial producida y comercializable como signo distintivo. Esa clasificación de los individuos según capacidades adquisitivas hace del consumo un perfecto medio de integración y control social que sustituye con ventaja a cualquier ideología como ritual jerárquico.

5. Génesis ideológica de las necesidades ${ }^{18}$ : las necesidades son la coartada del consumo. El hombre consume porque está necesitado. La postura psicologicista no llega en sus análisis más allá de la cuestión de la manipulación de la publicidad que induciría a un consumo desmedido. Pero esta explicación no da cuenta de fenómenos como la moda. El concepto de necesidad es ideológico, hay que interpretarlo como función inducida en los individuos por la lógica del sistema. No como fuerza consumidora liberada por la sociedad de abundancia, sino como fuerza productora requerida por el funcionamiento del propio sistema. Sólo hay necesidades porque el sistema las necesita. La satisfacción de los impulsos biológicos se convierte en una institución social. En el proceso de satisfacción de sus necesidades, que es el de su creación, la sociedad expresa mediante relaciones simbólicas su estructura, su propia jerarquía. Las necesidades no apuntan tanto a los objetos como a los valores y su satisfacción tiene el sentido de una adhesión a esos valores. El deseo de prestigio y diferenciación social es la necesidad básica.

Contra toda apariencia, la sociedad de consumo no es una sociedad de abundancia, pues produce una pauperización psicológica. No es productora de bienes sino de privilegios y por tanto de penuria. Cuanto más se consume más lejos se siente el término final que sería la abundancia. En nuestras sociedades diferenciadas, el intercambio añade a la falta individual, pues toda cosa poseída es relativizada por relación a las otras de la serie.

6. La compulsión al gozo y el narcisismo: para el hombre consumidor ha nacido una nueva ética: la de la compulsión al gozo, que ha sustituido la tradi-

18. - BAUdRILlARD, J., La génesis ideológica de las necesidades. Anagrama, Barcelona 1976. 
cional ética del trabajo. El gozo es, en este caso, el resultado de la movilización de sus capacidades adquisitivas; «si no consume no tiene derecho a ser feliz». El sistema industrial adiestró a la masa del s. XIX como fuerza de trabajo, hoy lo hace como fuerza de consumo. Se hace creer que un abismo separa una etapa de la otra. Los temas del gasto, el gozo, el no-cálculo (compre hoy, gaste mañana), sustituyen a la moral puritana del ahorro, trabajo y patrimonio. $\mathrm{Pe}$ ro es sólo una apariencia de revolución humana. Simplemente: los nuevos valores son la mediación obligada de la reproducción del sistema. El narcisismo del individuo en la sociedad de consumo no es fruición de la singularidad, es refracción de trazos colectivos. Se invita al individuo a gozar de sí, a complacerse en sí para complacer a los demás. Sobre las mujeres se ejerce especialmente la invitación a la complacencia, por medio del mito de la «mujer». Se vende «mujer» a la mujer. Creyendo pintarse, perfumarse, es decir, crearse, la mujer se consume a sí misma. La relación con los otros y con uno mismo se vuelve consumida. Toda relación espontánea y natural basada en cualidades reales, desaparece, sustituida por una relación mediatizada por un sistema de signos. Si la mujer se consume es que su relación con ella misma está objetivada, alimentada por signos que constituyen el modelo de lo femenino, verdadero objeto de consumo. Ahora cada uno encontrará su personalidad en el cumplimiento del modelo. También a los jóvenes se les dará a consumir «joven». No cabe mayor alienación, ni tampoco mayor ironía.

En una sociedad capitalista, el status general de la propiedad privada se aplica igualmente al cuerpo y a la representación mental de él; el cuerpo como capital y fetiche. El cuerpo se convierte en objeto de un trabajo de solicitud, bajo apariencia de liberación. El imperativo de la belleza que a él se le aplica consiste en hacer valer al cuerpo a través del revestimiento narcisista. Gracias a ello el deseo se muda en demanda de objetos. El cuerpo se convierte en el mito director de una ética de consumo, despierta valores irresponsables que orientan conductas de consumo. La liberación del cuerpo aparece entonces como claramente ambigua. Constituido en objeto sagrado sustituye al alma como objeto de salvación. Ésta exige una solicitud que puede ser represiva, pues pasa por una reapropiación funcional del cuerpo, es decir, no según finalidades autónomas sino de acuerdo con los objetivos del capitalismo: para hacerlo fructificar. Se le manipula como patrimonio, significante de status, objeto de inversión. Su liberación pasa por los objetos: higiene, maquillaje, bronceado, deporte, salud, etc.: compre y «vous serez bien dans votre peau» ${ }^{19}$. La higiene y todos sus fantasmas, el adelgazamiento, etc., hacen del

19. BAUDRILlaRd, J., La societé de consomation. 
cuerpo un objeto amenazante que es necesario vigilar con fines estéticos (funcionales). El cuerpo y el sexo son consumidos en cuanto desubstancializados, liberados de su sentido profundo y abstraidos de la relación interpersonal.

7. La alienación. El consumo es vivido como ideología democrática: «El consumo toma la apariencia de unción de las necesidades humanas y, por lo tanto, de función empírica universal. Sobre esta base, se podrá incluso aventurar que tiene por función corregir las desigualdades sociales de una sociedad estratificada: frente a la jerarquía de poder y del origen social, habría la democracia del ocio, de la autopista y de refrigerador. La lógica cultural de clase en sociedad burguesa siempre se ha fundado sobre la coartada democrática de los universales. La religión fue un universal. Los ideales humanistas de libertad y de igualdad fueron universales. Hoy, el universal adopta la evidencia absoluta de lo concreto: son las necesidades humanas y los bienes materiales y culturales los que a él responden. Es el universal del consumo ${ }^{20}$. Tras esa coartada democrática se esconde la realidad de que la alienación es la estructura misma de la sociedad de consumo. Una vez que se ha pactado con el ambiente maternal y benéfico de la sociedad de abundancia, el individuo será abolido en la contemplación de los signos de status, tras el escaparate. La democracia implantada por el universal «consumo» dejará siempre intacta la estructura de poder y decisión. La pobreza aparecerá como residual. En realidad el sistema ignora los contenidos sociales, sólo conoce las condiciones de su propia supervivencia.

\section{LA ALTERNATIVA ES LA CONCIENCIA CRÍTICA}

En nuestra sociedad los grupos sociales se aglutinan alrededor de diversos intereses económicos y desde ellos dan lugar a concepciones ideológicas que velan, más que aclaran, el sentido de la actividad a ellas vinculada. Podemos decir que los llamados círculos ideológicos se apoderan de nuestra conciencia ${ }^{21}$. En el seno de ellos, las comprensiones de la vida o teorías nace para justificar una praxis y ésta a su vez genera dichas comprensiones para ocultar su verdadero significado. ¿Cómo cuestionar esta circularidad? ¿Cómo captar el marco ideológico en el que se mueven nuestras vidas? Dos son los pasos a dar:

a) La sospecha: ella debe morder sobre nuestra teología. Debemos preguntarnos si lo que decimos en nuestras convivencias, ejercicios espirituales,

20. Baudrillard, J., Crítica de la economía política del signo. s. XXI, México 1974.

21. Libanio, J.B., Formación de la conciencia crítica. v. II, CLAR, Bogotá 1980. 
etc., tiene su raíz en los intereses de un grupo social, si está condicionado por nuestra propia posición social. Para ello habrá que tener en cuenta que una teología intimista que apela a la conversión de los corazones para que las personas luego cambién el mundo, no sólo es una teología ingenua (la conciencia y la realidad social son dos momentos simultáneos que no pueden desligarse) sino que defiende los intereses del poder. La religión que no se tiene por política es que hace la política del poder. Los intereses de clase media impregnan nuestro pensamiento. Una teología intimista hace el juego a la modernidad al sancionar la retirada a lo privado. Dios se convierte, gracias a esta teología, en funcional para el sistema de consumo, pues recompone la interioridad herida de la persona para que éste pueda funcionar.

b) Experiencia de lo diferente: hacer que las personas entren en contacto con nuevas experiencias. No basta colocar a la persona ante la injusticia, la tortura, etc. hace falta dotarla de un nuevo aparato teórico. Las nuevas experiencias se afrontarán de lo contrario con mentalidades antiguas (asistenciales). Son necesarias teorías divergentes identificadas con los intereses de los pobres. La censura y la represión son instrumentos eficaces en el esfuerzo por evitar sospechas sobre prácticas y teorías dominantes. La pedagogía de la experiencia nos muestra que son necesarios los aspectos teóricos y prácticos (ni hechos brutos ni pura teoría).

¿Por qué nos tienta el inmovilismo? Lo nuevo aparece como una amenaza. Nuestra identidad es amenazada por la alteridad. Un modo de afirmarse es el rechazo de lo opuesto. El concepto tradicional de verdad, ley, norma, pretende captar la realidad tal cual es, por ello no acepta la disidencia. Se excluye así la apertura a lo diferente. Los mecanismos afectivos tienden a preservar la propia consistencia. Pero la salvación está fuera de mí, en la apertura a lo otro. En la base de la apertura está el amor.

No sólo los individuos, también la sociedad dispone de medios para controlar la disidencia:

a) La terapia: es un modo de disminuir la tensión provocada por la crisis de identidad. Existen muchos mecanismos terapéuticos. Se trata de reforzar la adhesión afectiva para que se abandone toda actitud de disidencia, manteniendo el ánimo de la gente dentro de las concepciones biográficas vigentes. Busca desanimar a los enemigos. Así, un gran medio terapéutico es la TV que consigue mantener las calles vacías e impregnar las conversaciones de los valores que al sistema económico más le convienen.

b) El control social: la vida religiosa es propensa a los controles, pues está amenazada por el estilo normal de vivir. Existen mecanismos coercitivos y punitivos que castigan al disidente de forma real o simbólica: excomunión, pecado, etc. 
c) La temática de la conversación; es básica para mantener una determinada conciencia. Cada grupo crea un bagaje para su conversación gracias al cual los valores, ideas y modos de pensar circulan entre sus miembros. El éxito de los grupos cristianos depende de su capacidad de crear un repertorio de temas cristianos que alimenten su fe, de lo contrario asumirán los valores dominantes de la conversación normal. Muchos jóvenes abandonan su fe al no encontrar una temática cristiana de conversación. La fuerza de la conversación depende de lo significativos que sean los otros, que en las conversaciones hacen de eco a un universo de valores. Son los grupos de referencia los que suministran el bagaje para la conversación. La conversación diaria cara a cara se sustituye con las convivencias, grupos, etc. Éstos son cada vez más importantes, en la medida en que los valores cristianos ya no circulan en el medio ambiente.

Cuando las terapias preservan estructuras injustas son alienantes. Para el cristiano, la temática de conversación debe ser crítica. Es necesario neutralizar los mecanismos terapéuticos y de control social, tal tarea corresponde al educador que propiciará nuevas identidades biográficas para sus educandos, más acordes con su espíritu de libertad y justicia. Para el educando la práctica libre y autónoma es con frecuencia insoportable y por ello crea mecanismos de defensa ante el cambio, que dificultan el asumir una personalidad solidaria (y no narcisista). Se trata de mecanismos psicológicos por los que el hombre intenta escapar de las condiciones de su propia existencia, dimitir de su yo. Existen unos mecanismos de fuga socialmente elaborados y que se ofrecen como respuesta a las situaciones de la vida. El desarrollo humano supone una progresiva posesión de sí mismo más allá de todo estado de simbiosis. El mecanismo de fuga establece la imposibilidad de un proceso de individualización que termine en la creación de una persona solidaria. Para la postmodernidad, la individualización hedonista es el nuevo proceso de socialización, ella hace posible la creación de un inmenso desierto social y una anemia total respecto a la compasión, origen de todo proceso de liberación. La autoinversión afectiva vacía el espacio social y lo deja en manos del poder. Esta individualización o proceso de atomización social radical que elimina toda constricción institucional, disuelve tradiciones y sistemas ideológicos, provoca una deserción de lo sagrado sin precedentes. La fragmentación del sentido y la pluralidad de ofertas permite que cada uno componga su vida a la carta, con total libertad combinatoria. La personalización ha fracturado la sociedad disciplinaria limitando el individualismo hedonista. Entre los mecanismos de fuga más relevantes tenemos:

a) El autoritarismo se establece una relación simbiótica. Por ella se incorpora al propio ser las características poderosas del otro. El sujeto disfruta 
de una pseudoautonomía. Las fatalidades se racionalizan como ley natural o voluntad divina. Existe una autoridad anónima de especial importancia en la democracia: la opinión pública, el consejero mágico del que se depende en exceso o la autoridad internalizada, no nos permite desarrollarnos en autonomía.

b) La destructividad consiste en la fuga de la individualidad y la libertad mediante la eliminación o la destrucción del otro. Se racionaliza como deber, amor, patriotismo, etc.

c) El conformismo: es la fuga de la personalidad mediante la adopción plena de los patrones sociales establecidos. Se trata del mecanismo más común entre las personas normales. El autómata no se angustia, pues es común a muchos miles de seres.

\section{CONCLUSIÓN}

Los signos de los tiempos son un periódico de lectura obligada. Al norte, nuevas tecnologías, narcisismo, paro. Al sur, hambre, armas, deuda, indignación y donde hay fuerzas, insurrección. En el este un Marx sin Bakunin degeneró en Stalin. En el oeste, un Bakunin sin Marx degeneró en Nietzsche ${ }^{22}$. Todo ello, no es un fenómeno exterior a la Iglesia. Los aires de postvaticanidad que parecen azotarla presagian que se puede llegar a sancionar equivocadamente la postmodernidad. Sólo la recuperación de la utopía evangélica de la paz y la justicia, ajena a dualismos que terminan por arrinconar a la religión en el campo de lo espiritual y personal, puede devolvernos a nuestra dimensión original como profetas del Reino que no es de este mundo, pero que comienza aquí.

Pedro MAZA BAZÁN

Móstoles

22. GonzÁlez Faus, J.I., o.c. 